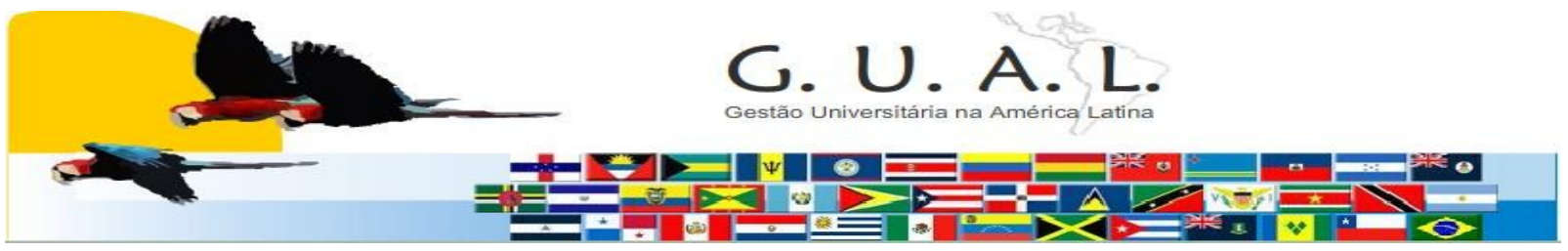

ISSN 1983-4535

\title{
APLICAÇÃO DO MODELO DE AVALIAÇÃO INTEGRADO AO PLANEJAMENTO ANUAL NA FACULDADE DA SERRA GAÚCHA (FSG): UM ESTUDO DE CASO
}

Cláudia Medianeira Cruz Rodrigues, Doutora

Universidade Federal do Rio Grande do Sul claudia.rodrigues@producao.ufrgs.br

\begin{abstract}
RESUMO
Este artigo possui como objetivo verificar a funcionalidade do modelo de avaliação integrado ao planejamento anual proposto por Rodrigues (2003) em uma instituição privada de ensino superior, como forma de observar o desempenho dos elementos que compõem os pilares propostos pelo modelo, ou seja: (i) integração entre os elementos de avaliação e planejamento; (ii) uso de indicadores orientados ao planejamento; (iii) seqüenciamento das atividades anuais de avaliação e planejamento; (iv) estabelecimento do ciclo integrado de avaliação e planejamento; e (v) integração dos recursos humanos nos processos de avaliação e planejamento. A coleta de dados envolveu duas etapas: (1) estudo de caso realizado na Faculdade da Serra Gaúcha/ Caxias do Sul-RS, no período 2004-2006; (2) entrevistas semiestruturadas com a Comissão Própria de Avaliação, envolvendo representantes docentes, discentes e técnico-administrativos. Os resultados apontam a validade do modelo para este segmento de IES, necessitando de pequenos ajustes em termos operacionais. Verificou-se que o pilar $(v)$ da proposta aplicada foi um dos que mais interferiu na condução dos processos, ou seja, o pilar relacionado a gestão de pessoas, onde houve dificuldade principalmente na compreensão do que seja de fato uma 'avaliação institucional' e na importância da conscientização dos setores em relação a fornecer informações no tempo solicitado pela comissão. Desta forma, outros pilares da proposta ficaram prejudicados exatamente pela falta de cultura da instituição em perceber que o ciclo avaliação-planejamento é algo contínuo, em constante aprimoramento.
\end{abstract}

Palavras-chave: Avaliação institucional. Planejamento anual. SINAES. 


\section{INTRODUÇÃO}

O sistema de ensino superior no Brasil é bastante complexo, regulado por leis, decretos, portarias, emendas constitucionais e medidas provisórias que embasam e sustentam o funcionamento das instituições. Tal complexidade também pode ser atribuída à diversidade das instituições de ensino, que foram amparadas pela Lei $\mathrm{n}^{0} 9.394$ que definiu as Diretrizes e Bases da Educação Nacional, aprovada em dezembro de 1996. A partir da LDB foram criados os centros universitários e as faculdades integradas, sendo os cursos seqüenciais preconizados pela LDB, normatizada pelo Conselho Nacional de Educação em dezembro de 1998 e regulamentada em 1999.

As instituições de ensino superior (IES) podem ser classificadas em públicas e privadas. A LDB no artigo 20 faz o enquadramento das instituições privadas de ensino superior nas seguintes categorias: (1) particulares em sentido estrito, assim entendidas as que são instituídas e mantidas por uma ou mais pessoas físicas ou jurídicas de direito; (2) comunitárias, assim entendidas as que são instituídas por grupos de pessoas físicas ou por uma ou mais pessoas jurídicas, inclusive cooperativas de professores e alunos que incluam na sua entidade mantenedora representantes da comunidade; (3) confessionais, assim entendidas as que são instituídas por grupos de pessoas físicas ou por uma ou mais pessoas jurídicas que atendem a orientação confessional e ideologia específicas; (4) filantrópicas, na forma da lei.

Os representantes das universidades comunitárias, buscando diferenciar-se do chamado ensino privado empresarial, passam a denominar suas instituições como públicas não-estatais, ou seja, caracterizado pelos trabalhos sociais desenvolvidos junto às populações de baixa renda e, assim, buscam aproximar-se do setor público estatal, distanciando-se do segmento estritamente particular. Com esta denominação (comunitárias) buscam conquistar um espaço que não pertence ao estritamente público e nem ao estritamente privado (BITTAR, 2001).

Levando-se em consideração a diversidade de IES, assim como a importância do segmento de instituições comunitárias, estruturou-se em 2004 um modelo de avaliação institucional integrado ao planejamento de curto prazo, voltado para a realidade das Universidades Comunitárias Gaúchas - UCGs. Para construir o modelo, foram estudadas três instituições do COMUNG - Consórcio das Universidades Comunitárias Gaúchas (UCGs) e instituições latino-americanas como a UDELAR (Universidade de La República, Montevideo/

Rev. GUAL., Florianópolis, v.4, n. 2, p.29-52, mai/ago. 2011 


\section{APLICAÇÃO DO MODELO DE AVALIAÇÃO INTEGRADO AO PLANEJAMENTO ANUAL NA FACULDADE DA SERRA GAÚCHA (FSG): UM ESTUDO DE CASO}

Uruguai) e a UNR (Universidade Nacional de Rosário/ Argentina) e revisados as bases legais que sustentam o Sistema Nacional de Avaliação do Ensino Superior - o SINAES que foi instituído em 14 de abril de 2004, através da Lei nº 10.861, assim como o PAIUNG (Programa de Avaliação Institucional das Universidades Comunitárias Gaúchas).

O SINAES é um sistema de avaliação global e integrada das atividades acadêmicas, composto por três processos diferenciados: (i) avaliação das IES - AVALIES; (ii) avaliação dos cursos de graduação - ACG e (iii) avaliação do desempenho dos estudantes - ENADE. Cabe salientar que o Consórcio das Universidades Comunitárias (COMUNG) possuía um programa específico de avaliação, o PAIUNG, que foi criado em 1994, baseado no Programa de Avaliação Institucional das Universidades Brasileiras (PAIUB), que foi criado em 1993.

O modelo proposto integra avaliação ao processo de planejamento de curto prazo, apresentando cinco pilares que devem ser observados pelas instituições para que a avaliação aconteça integrada ao planejamento, a saber: (1) integração entre os elementos de avaliação e planejamento; (2) uso de indicadores orientados ao planejamento; (3) seqüenciamento das atividades anuais de avaliação e planejamento; (4) estabelecimento do ciclo integrado de avaliação e planejamento; e (5) integração dos recursos humanos nos processos de avaliação e planejamento.

Esses conceitos são gerais, voltados à integração das atividades de avaliação e planejamento e, embora o estudo tenha sido realizado em instituições comunitárias gaúchas, as quais proporcionaram vivências para a elaboração da abordagem integrada, acredita-se que a mesma pode ser aplicada em outras instituições de ensino superior, de natureza pública ou privada. Para tanto, o que deve ser feito são adequações nos elementos que constituem os pilares propostos.

Os indicadores sugeridos para compor o sistema foram baseados na concepção do BSC - Balanced Scorecard proposto por Kaplan e Norton (1997) que prevê o uso equilibrado de indicadores em perspectivas: clientes, processos internos, aprendizado e crescimento e financeira. No entanto, tal abordagem permite a eliminação e acréscimo de outras perspectivas, de acordo com a finalidade da organização.

Este artigo objetiva analisar a funcionalidade do modelo integrado de avaliação $\mathrm{x}$ planejamento anual em uma instituição privada de ensino superior, como forma de observar o desempenho dos elementos que compõem os pilares propostos pelo modelo de Rodrigues

Rev. GUAL., Florianópolis, v.4, n. 2, p.29-52, mai/ago. 2011 
(2003) e que foram criados para uma realidade específica de Instituição de Educação Superior, o segmento das universidades comunitárias gaúchas (UCGs). Para tanto, o artigo apresenta na seção 2 o referencial teórico, na seção 3 o método de pesquisa, na seção 4 os resultados e, na seção 5 as considerações finais.

\section{REFERENCIAL TEÓRICO}

\subsection{O Modelo Integrado de Avaliação x Planejamento Anual}

A seguir são apresentados os pilares que fazem parte do modelo de avaliação integrado ao planejamento anual proposto por Rodrigues (2003).

\subsubsection{Primeiro pilar - Integração entre os elementos de avaliação e planejamento}

\section{Quadro 1}

Integração entre os elementos de avaliação e planejamento

\begin{tabular}{|c|c|}
\hline Avaliação Anual & Planejamento Anual \\
\hline Pesquisa & Pesquisa \\
\hline Infraestrutura de apoio & Infraestrutura de apoio \\
\hline Fontes de financiamento & Fontes de financiamento \\
\hline Qualificação dos pesquisadores & Qualificação dos pesquisadores \\
\hline $\begin{array}{l}\text { Participação em congressos/ encontros/ } \\
\text { jornadas }\end{array}$ & Participação em congressos/ encontros/ jornadas \\
\hline Participação discente em pesquisas & Participação discente em pesquisas \\
\hline Realização de eventos científicos & Realização de eventos científicos \\
\hline Projetos de pesquisa & Projetos de pesquisa \\
\hline Publicações & Publicações \\
\hline Extensão & Extensão \\
\hline Infraestrutura de apoio & Infraestrutura de apoio \\
\hline Demanda de cursos & Ofertas de cursos \\
\hline Cursos ofertados & Ofertas de cursos \\
\hline Eventos de extensão & Eventos de extensão \\
\hline Prestação de serviços & Prestação de serviços \\
\hline Produção e publicações de extensão & Produção e publicações de extensão \\
\hline Ensino de Graduação & Ensino de Graduação \\
\hline Projeto pedagógico & Revisão do projeto pedagógico \\
\hline Infraestrutura de apoio & Infraestrutura de apoio \\
\hline Qualificação do quadro docente & Qualificação do quadro docente \\
\hline Demanda de cursos & Oferta de cursos \\
\hline
\end{tabular}

continua 
continuação

\begin{tabular}{|l|l|}
\hline $\begin{array}{l}\text { Participação discente em publicações, } \\
\text { congressos, semanas acadêmicas, etc. }\end{array}$ & $\begin{array}{l}\text { Participação discente em publicações, } \\
\text { congressos, semanas acadêmicas, etc. }\end{array}$ \\
\hline $\begin{array}{l}\text { Participação discente em atividades } \\
\text { curriculares e extra-curriculares }\end{array}$ & $\begin{array}{l}\text { Participação discente em atividades curriculares } \\
\text { e extra-curriculares }\end{array}$ \\
\hline Desempenho dos cursos e disciplinas & Alterações curriculares \\
\hline Formação de alunos & Formaturas, mídia \\
\hline \multicolumn{1}{|c|}{ Ensino de Pós-Graduação } & \multicolumn{1}{c|}{ Ensino de Pós-Graduação } \\
\hline Projeto pedagógico & Revisão do projeto pedagógico \\
\hline Infraestrutura de apoio & Infraestrutura de apoio \\
\hline Qualificação do quadro docente & Qualificação do quadro docente \\
\hline Demanda de cursos & Oferta de cursos \\
\hline $\begin{array}{l}\text { Participação em congressos, semanas } \\
\text { acadêmicas, etc. }\end{array}$ & $\begin{array}{l}\text { Participação em congressos, semanas } \\
\text { acadêmicas, etc. }\end{array}$ \\
\hline Desempenho dos cursos e disciplinas & Alterações curriculares \\
\hline Publicações & Publicações \\
\hline \multicolumn{1}{|c|}{ Gestão } & Revisão do PDI \\
\hline Políticas institucionais & Revisão da estrutura organizacional \\
\hline Estrutura organizacional & Infraestrutura de apoio \\
\hline Infraestrutura de apoio & $\begin{array}{l}\text { Revisão do plano de capacitação docente e } \\
\text { funcionários }\end{array}$ \\
\hline Capacitação de docentes e funcionários \\
\hline Qualificação de docentes e funcionários & $\begin{array}{l}\text { Revisão do quadro docente e funcionários } \\
\text { (contratação/ dispensa) }\end{array}$ \\
\hline Volume de recursos financeiros & Fontes de financiamento \\
\hline Distribuição de recursos financeiros & Distribuição de recursos financeiros \\
\hline Imagem da instituição junto à comunidade & Consolidação da imagem institucional \\
\hline
\end{tabular}

\subsubsection{Segundo pilar - Uso de indicadores orientados ao planejamento}

\section{Quadro 2}

\section{Uso de indicadores orientados ao planejamento}

\begin{tabular}{|l|l|}
\hline \multicolumn{2}{|c|}{ Avaliação Anual } \\
\hline & $\begin{array}{l}\text { Pesquisa } \\
\text { Laboratórios (m2/professor-pesquisador); R\$ em } \\
\text { equipamentos/ (professor-pesquisador); idade média dos } \\
\text { equipamentos (meses); acervo bibliográfico: } \\
\text { periódicos/professor-pesquisador }\end{array}$ \\
\hline Fontes de financiamento & $\mathrm{R} \$$ por professor-pesquisador \\
\hline
\end{tabular}

continua

Rev. GUAL., Florianópolis, v.4, n. 2, p.29-52, mai/ago. 2011 


\begin{tabular}{|c|c|}
\hline $\begin{array}{l}\text { Qualificação dos } \\
\text { pesquisadores }\end{array}$ & $\begin{array}{c}\text { Titulação (\% graduados, especialistas, mestres, doutores); } \\
\text { experiência não acadêmica (anos) }\end{array}$ \\
\hline $\begin{array}{l}\text { Participação em } \\
\text { congressos/ encontros/ } \\
\text { jornadas }\end{array}$ & $\begin{array}{c}\mathrm{n}^{\mathrm{o}} \text { de participações de discentes/total de discentes; } \mathrm{n}^{\mathrm{o}} \text { de } \\
\text { participações docentes/total de docentes }\end{array}$ \\
\hline $\begin{array}{l}\text { Participação discente em } \\
\text { pesquisas }\end{array}$ & $\begin{array}{l}\mathrm{n}^{\mathrm{o}} \text { de alunos participando de projetos de pesquisa/total de } \\
\text { alunos; } \mathrm{n}^{\circ} \text { de bolsas de iniciação científica/total de alunos }\end{array}$ \\
\hline $\begin{array}{l}\text { Realização de eventos } \\
\text { científicos }\end{array}$ & $\begin{array}{c}\mathrm{n}^{\mathrm{o}} \text { de eventos/curso; } \mathrm{n}^{\mathrm{o}} \text { de inscritos nos eventos/total de } \\
\text { discentes }\end{array}$ \\
\hline Projetos de pesquisa & $\begin{array}{c}\mathrm{n}^{\mathrm{o}} \text { de projetos financiados e não financiados/professor- } \\
\text { pesquisador; \% de professores envolvidos em projetos de } \\
\text { pesquisa; } \mathrm{n}^{\mathrm{o}} \text { de pesquisadores envolvidos nos projetos; Carga } \\
\text { horária dos pesquisadores dedicada a projetos }\end{array}$ \\
\hline Publicações & $\begin{array}{c}\mathrm{n}^{\mathrm{o}} \text { de artigos publicados em revistas indexadas/docente; } \mathrm{n}^{\circ} \\
\text { artigos publicados em anais de eventos/docente; } \mathrm{n}^{\circ} \text { capítulos de } \\
\text { livros/docente, } \mathrm{n}^{\mathrm{o}} \text { livros publicados/docente; } \mathrm{n}^{\mathrm{o}} \text { registros e } \\
\text { patentes/docente }\end{array}$ \\
\hline \multicolumn{2}{|r|}{ Extensão } \\
\hline Infraestrutura de apoio & $\begin{array}{l}\text { Espaço físico (m2/docente), } \mathrm{R} \$ \text { em equipamentos/docente; } \\
\text { idade média dos equipamentos (meses) }\end{array}$ \\
\hline Demanda de cursos & $\%$ de preenchimento das vagas ofertadas \\
\hline Cursos ofertados & $\mathrm{n}^{\mathrm{o}}$ de alunos atendidos/docente; horas ofertadas/docente \\
\hline Eventos de extensão & $\mathrm{n}^{\mathrm{o}}$ de participantes atendidos/docente; horas ofertadas/docente \\
\hline Prestação de serviços & $\mathrm{n}^{\mathrm{o}}$ atendimentos/docente; $\mathrm{R} \$ /$ docente \\
\hline $\begin{array}{l}\text { Produção e publicações de } \\
\text { extensão }\end{array}$ & $\begin{array}{l}\mathrm{n}^{\mathrm{o}} \text { de vídeos e aplicativos multimídias /docente, } \mathrm{n}^{\mathrm{o}} \text { de } \\
\text { softwares, } \mathrm{n}^{\mathrm{o}} \text { de relatórios técnicos/docente, } \mathrm{n}^{\mathrm{o}} \\
\text { produtos/docente }\end{array}$ \\
\hline \multicolumn{2}{|r|}{ Ensino de Graduação } \\
\hline Projeto pedagógico & $\begin{array}{l}\% \text { de cursos com projeto pedagógico; \% de projetos } \\
\text { pedagógicos atualizados no ano }\end{array}$ \\
\hline Infraestrutura de apoio & $\begin{array}{l}\text { Salas (m2/aluno); laboratórios (m2/aluno); } \mathrm{n}^{\circ} \text { computadores } \\
\text { com acesso a internet/ aluno; } \mathrm{R} \$ \text { em equipamentos/aluno; } \\
\text { idade média dos equipamentos (meses); acervo bibliográfico } \\
\text { da graduação/total de alunos }\end{array}$ \\
\hline
\end{tabular}




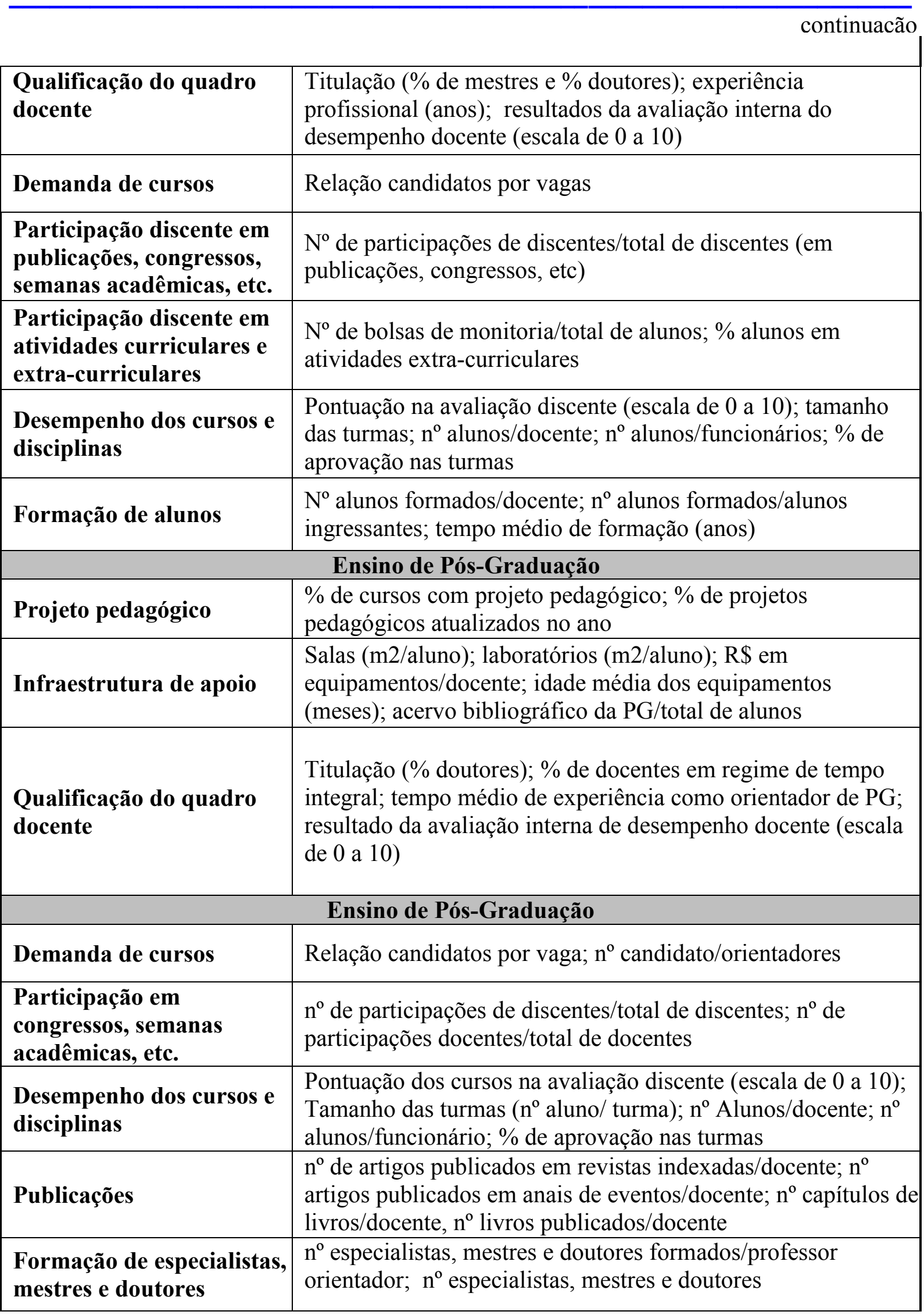




\begin{tabular}{|c|c|}
\hline \multicolumn{2}{|r|}{ continuação } \\
\hline & $\begin{array}{l}\text { formados/alunos ingressantes; tempo médio de formação } \\
\text { (anos) }\end{array}$ \\
\hline \multicolumn{2}{|r|}{ Gestão } \\
\hline Políticas institucionais & $\%$ de atingimento das metas propostas \\
\hline Estrutura organizacional & $\begin{array}{l}\text { Avaliação do quadro administrativo (quantidade e qualidade); } \\
\text { avaliação do clima organizacional (escala de } 0 \text { a } 10 \text { ) }\end{array}$ \\
\hline Infraestrutura de apoio & $\begin{array}{l}\text { Área construída/aluno (m2 /aluno); área em construção/aluno } \\
\text { (m2 /aluno); área de estacionamento/aluno ( } \mathrm{m} 2 \text { /aluno); área } \\
\text { para lazer/aluno (m2 /aluno); avaliação qualitativa dos prédios } \\
\text { e equipamentos }\end{array}$ \\
\hline $\begin{array}{l}\text { Capacitação de docentes e } \\
\text { funcionários }\end{array}$ & $\begin{array}{l}\% \text { de docentes e funcionários em formação nos níveis } \\
\text { graduado, especialista, mestrado e doutorado }\end{array}$ \\
\hline $\begin{array}{l}\text { Qualificação de docentes e } \\
\text { funcionários }\end{array}$ & $\begin{array}{l}\text { Titulação (\% graduados, especialistas, mestres, doutores); \% } \\
\text { em regime de tempo integral; experiência profissional (anos); } \\
\text { resultados da avaliação interna do desempenho de docentes e } \\
\text { funcionários (escala de } 0 \text { a 10) }\end{array}$ \\
\hline $\begin{array}{l}\text { Volume de recursos } \\
\text { financeiros }\end{array}$ & $\begin{array}{l}\text { Resultado do balanço anterior (resultado financeiro em } \mathrm{R} \$ \text { ); } \\
\text { investimentos (R\$/aluno); inadimplência (\%) }\end{array}$ \\
\hline $\begin{array}{l}\text { Distribuição de recursos } \\
\text { financeiros }\end{array}$ & $\begin{array}{l}\text { Distribuição por dimensão (graduação, pós, pesquisa e } \\
\text { extensão), em \%; distribuição por área de conhecimento } \\
\text { (R\$/total de alunos) }\end{array}$ \\
\hline $\begin{array}{l}\text { Imagem da instituição } \\
\text { junto à comunidade }\end{array}$ & $\begin{array}{l}\text { \% dos níveis de satisfação da comunidade, empresas e público } \\
\text { interno (alunos, professores e funcionários); resultados das } \\
\text { avaliações externas (provão, CRC, OAB, etc, pontuação } \\
\text { obtida) }\end{array}$ \\
\hline
\end{tabular}


DE CASO

2.1.3 Terceiro pilar - Seqüenciamento das atividades anuais de avaliação e planejamento

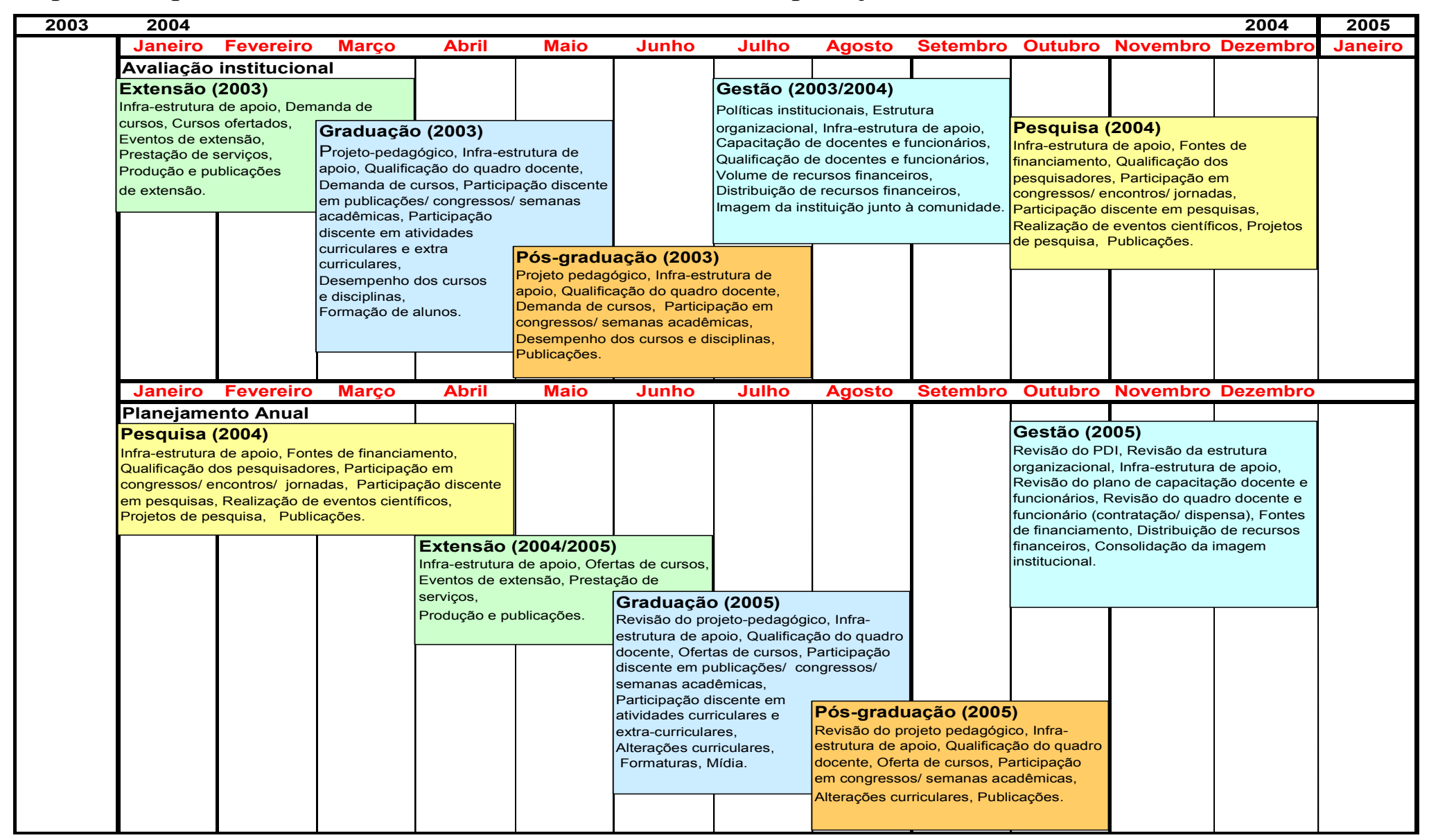

Figura 1 Seqüenciamento das atividades anuais de avaliação e planejamento 


\subsubsection{Quarto pilar - Estabelecimento do ciclo integrado de avaliação e planejamento}

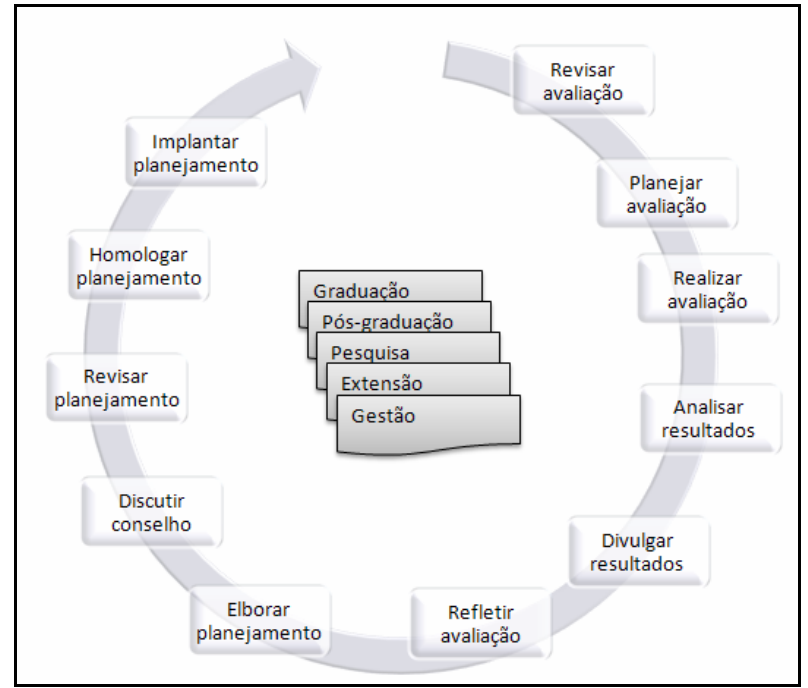

Figura 2 Estabelecimento do ciclo integrado de avaliação e planejamento

\subsubsection{Quinto pilar - Integração dos recursos humanos de avaliação e planejamento}

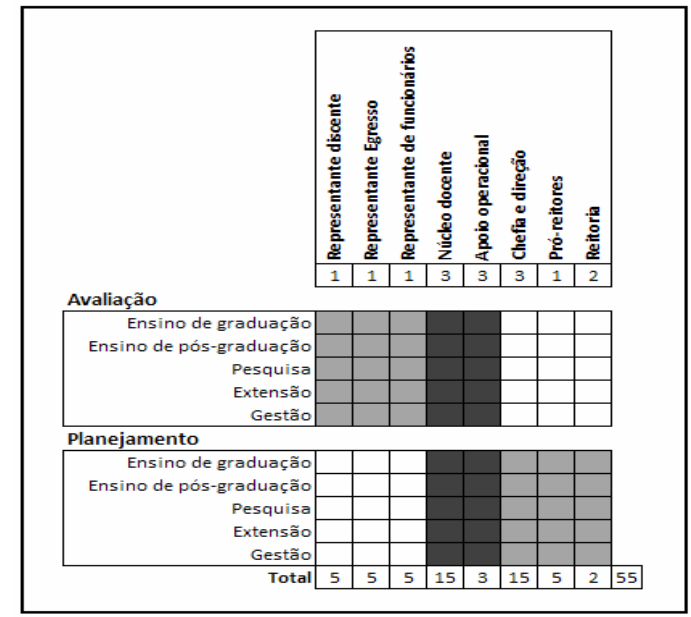

Figura 3 Integração dos recursos humanos de avaliação e planejamento

A Figura 6 ilustra a proposta que integra a avaliação ao planejamento anual, evidenciando os pilares propostos anteriormente e demonstrando o funcionamento do ciclo 'PDCA', conhecido como Ciclo Deming (Plan- planejar; Do- executar; Check- controlar e Action-agir), proposto a acontecer tanto no momento da avaliação quanto no momento do planejamento, assim como os públicos envolvidos e o horizonte temporal. 


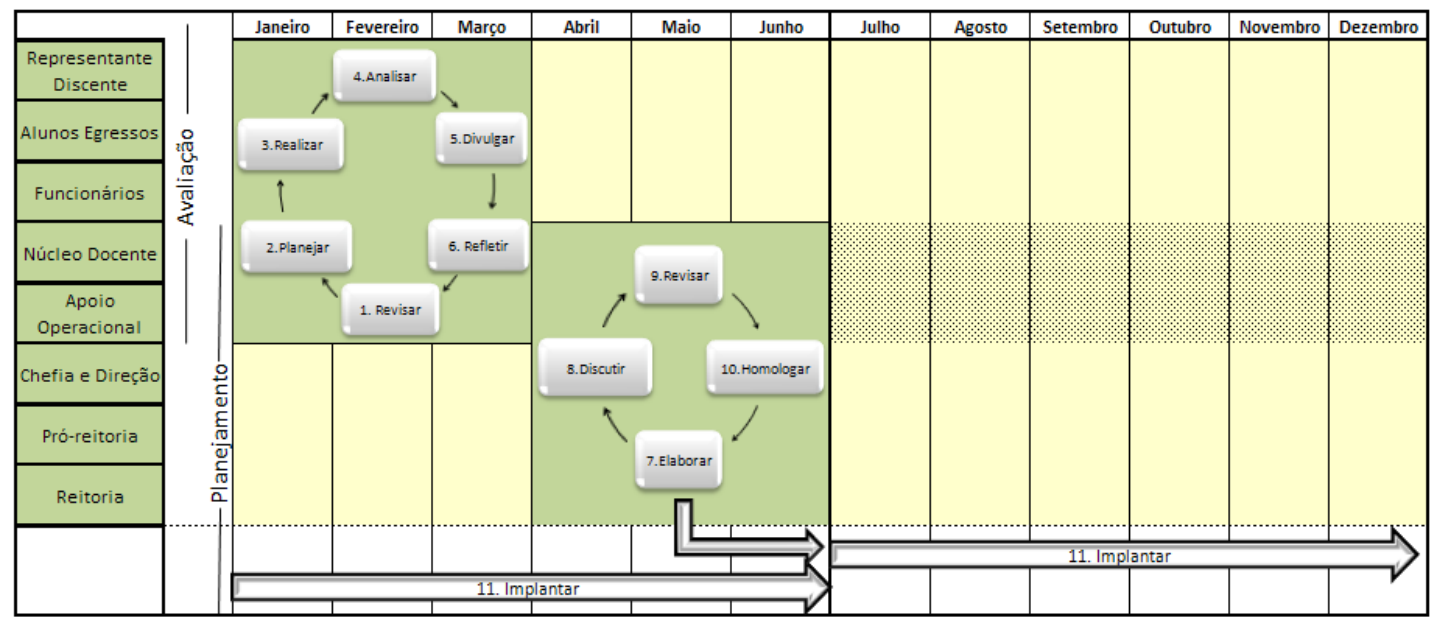

Figura 4 Proposta integrada de avaliação x planejamento anual

\section{MÉTODO DE PESQUISA}

Esta pesquisa caracteriza-se como sendo um estudo de caso, que no entender de Yin (2001, p. 32), “é uma investigação empírica que investiga um fenômeno contemporâneo dentro de seu contexto da vida real, especificando quando os limites entre o fenômeno e o contexto não estão claramente definidos", podendo incluir tanto estudos de caso único quanto de casos múltiplos. Também caracteriza-se como sendo uma pesquisa-ação tendo em vista a aplicação e acompanhamento do processo de avaliação junto à instituição definida como estudo piloto. De acordo com Thiollent (2005, p. 16), “uma pesquisa-ação é um tipo de pesquisa social com base empírica que é concebida e realizada em estreita associação com uma ação ou com a resolução de um problema coletivo e no qual os pesquisadores e participantes representativos da situação ou do problema estão envolvidos de modo cooperativo ou participativo".

O estudo de caso foi realizado na Faculdade da Serra Gaúcha-FSG, instituição privada de educação superior, localizada na cidade de Caxias do Sul/ RS, no período de 2004 à 2006, período em que o modelo proposto por Rodrigues (2003) que integra avaliação ao processo de planejamento de curto prazo foi aplicado, monitorado e avaliado.

O modelo de Rodrigues (2003) apresenta cinco pilares que devem ser observados pelas instituições para que a avaliação aconteça integrada ao planejamento, a saber: (1) integração entre os elementos de avaliação e planejamento; (2) uso de indicadores orientados ao planejamento; (3) seqüenciamento das atividades anuais de avaliação e planejamento; (4) 
estabelecimento do ciclo integrado de avaliação e planejamento; e (5) integração dos recursos humanos nos processos de avaliação e planejamento.

A coleta de dados, referente ao levantamento sobre a aplicação do modelo, visando levantar as fragilidades e potencialidades do mesmo, ocorreu através de entrevistas semiestruturadas com a Comissão Própria de Avaliação da Instituição (CPA) e alguns membros da comunidade acadêmica, nos meses de setembro à novembro do ano de 2007, totalizando 9 entrevistas. O público envolvido na coleta de dados foi: (i) diretor da faculdade, (ii) coordenador da CPA, (iii) representantes docentes, (iii) representantes discentes e (iv) representantes técnicos-administrativos.

O roteiro das entrevistas envolveu três blocos de perguntas referentes aos aspectos operacionais do modelo, aspectos de desempenho e aspectos emergentes, que são tratados na seção referente aos resultados.

As entrevistas foram gravadas e, posteriormente, transcritas, sendo examinadas pela técnica de análise de conteúdo. Salienta-se que o modelo na sua concepção original propõe 12 meses para a condução dos processos de avaliação e planejamento anual, no entanto, efetivamente a aplicação do modelo na Faculdade ocorreu em 18 meses, considerando-se atividades preliminares como de explicação/ capacitação geral sobre o seu funcionamento e estímulo ao desenvolvimento de uma cultura avaliativa, enfim, prepararam-se as pessoas e a Instituição para a atividade a ser desenvolvida.

\section{RESULTADOS}

A seguir apresentam-se os resultados obtidos a partir da aplicação do modelo integrado na FSG, onde são tratados: (i) caracterização da Instituição; (ii) a trajetória do processo avaliativo na Faculdade e, (iii) as potencialidades e fragilidades do modelo.

\subsection{A Faculdade da Serra Gaúcha (FSG)}

A FSG iniciou suas atividades educacionais no ano de 2000 e desde então suas ações estão voltadas prioritariamente ao ensino de graduação, oferecendo cursos de bacharelado, de licenciatura, e cursos que conferem grau específico relacionado à profissão em seu programa regular de ensino de graduação, sendo mantida pela Associação Educacional Santa Rita. A 
partir de janeiro de 2005, a sede e as atividades educacionais estão localizadas na Rua Os Dezoito do Forte, 2366, Bairro São Pelegrino, em Caxias do Sul, RS.

A Faculdade, a partir de 2001, atenta às necessidades educacionais em nível superior, alinha propostas inovadoras, enfocando em suas ofertas a convergência entre as necessidades do mercado e as possibilidades de empreendimento que podem ser lidas em sua realidade. A Mantenedora, ao oferecer suporte a este novo empreendimento educacional, acrescenta qualidade e inovação em sua oferta para a Educação Superior, demarcando a sua participação comunitária, através de uma prática diferencial para a Educação de Educadores (FSG, Relatório de Avaliação Institucional, 2006).

Possui os seguintes cursos de graduação: Administração, Arquitetura e Urbanismo, Biomedicina, Ciências Contábeis, Design, Enfermagem, Educação Física, Engenharia Civil, Engenharia de Produção, Fisioterapia, Psicologia, Terapia Ocupacional.

\subsection{A Trajetória do Processo Avaliativo na Faculdade da Serra Gaúcha}

\subsubsection{Aspectos Operacionais}

A avaliação institucional na FSG não se restringe a uma discussão atual, tendo em vista as orientações e exigências governamentais. Ao contrário, respeita inúmeras ações que vinham sendo desenvolvidas anteriormente. Basicamente, o processo envolvia uma prática de avaliação semestral das disciplinas, infraestrutura e instituição, que propiciava uma leitura das diferentes ações desenvolvidas (FSG, Relatório da Avaliação Institucional, 2006).

O início do processo de avaliação ocorreu no ano de 2000, quando a instituição aplicava o AVALIE, que é um instrumento de avaliação do aluno em relação à infraestrutura da IES e do desempenho do professor. Tal instrumento foi aperfeiçoado no ano de 2004, quando foi aplicado o modelo proposto por Rodrigues (2003) de avaliação integrado ao planejamento anual na instituição.

(...) sobre os processos de avaliação institucionais nós estávamos procurando um modelo, uma forma de realizar essa avaliação e ai com a sugestão de juntar avaliação com planejamento, nos deu uma luz de como poderia ser de uma forma que a avaliação não fosse segmentada, não fosse isolada das ações necessárias ao desenvolvimento, crescimento e operacionalização da instituição. Então, no sentido da avaliação, não só pra quem tem vivência do MEC, mas também para contribuir nas melhorias e no crescimento da

Rev. GUAL., Florianópolis, v.4, n. 2, p.29-52, mai/ago. 2011 
instituição. E o modelo que foi adotado, ele não está ainda na sua implementação perfeita, mas ele permite que ao longo do tempo, a avaliação sugira, recomende melhorias ao planejamento e vice-versa. Então haverá uma sinergia constantemente entre planejamento e avaliação. Levamos para a mantenedora e para o conhecimento do colegiado, implementamos em seguida, então me parece que agora estamos dando mais o rumo de direcionamento a esse trabalho dentro das linhas das diretrizes propostas lá no seu início (Entrevista com o Diretor da Faculdade, set, 2007).

O processo de avaliação institucional na faculdade segue o modelo integrado de avaliação x planejamento anual. Foram avaliados três anos (2003-2005), de acordo com o que previa o modelo, onde a instituição avaliou as cinco dimensões - ensino de graduação, pósgraduação, pesquisa, extensão e gestão - remetendo os dados para o planejamento anual. A análise de tais anos originou o Relatório de auto-avaliação institucional que foi encaminhado ao Governo Federal no início do ano de 2006 (FSG, 2006).

(...) ele permite que o próprio coordenador do curso seja o gestor de fato de todo curso e ai a instituição não necessita de grande estrutura ativa do coordenador do curso para o gerenciamento da instituição. Nós aqui estamos montando e contamos com esse chamamento para que o coordenador ele tenha informações à mão e tome as medidas necessárias à condição do curso e que haja reuniões semanais ao longo, são socializadas as dificuldades e diretrizes maiores e ao mesmo tempo o pedido de auxílio ou de recursos para essas necessidades do curso que são feitas nessas oportunidades. Mas o planejamento em si e o controle, se aquilo que foi planejado efetivamente está acontecendo que esteja na mão do coordenador do curso e que não haja a necessidade de outros departamentos, outras áreas, outros profissionais, dando esses subsídios para o coordenador. Isso faz com que os nossos cursos, a instituição, ela fique numa estrutura muito light (Entrevista com o Diretor da Faculdade, set, 2007).

A comissão própria de avaliação, em 2007, possuía a seguinte estrutura: um coordenador da CPA, dois representantes da comunidade externa, quatro representantes discentes, dois representantes docentes e quatro representantes técnicos-administrativos. Tal comissão é a responsável em articular o processo avaliativo, tendo para isso um regimento próprio de funcionamento que prevê a utilização de subcomissões de avaliação, na intenção de agilizar o processo, envolvendo todos os segmentos institucionais.

Em relação à avaliação institucional percebida pelo professor, as entrevistas permitiram analisar que ainda em sua grande maioria, os professores, técnicos-administrativos e alunos percebem a avaliação institucional como sinônimo do AVALIE, que é um 
instrumento específico que avalia a satisfação dos alunos em relação aos professores e a infraestrutura da instituição. Neste sentido, oportuno enfatizar que a instituição possui uma meta de desempenho que deve ser atingida.

(...) o que se procurou fazer de melhoria é que geralmente, nos semestres anteriores, a devolução para o professor, ela ocorria sempre no semestre seguinte, na primeira, segunda ou terceira semana de aula. E pra isso, o professor quase que programou o semestre dele de aula, já tem o material pronto. Então já em 2007/4, 2007/2, o que se procurou é, antes do término do semestre, o professor já tenha o resultado da avaliação (Entrevista com o Coordenador da CPA, set, 2007).

Nos relatos houve comentários que no início do processo de divulgação do modelo, havia muitas reuniões periódicas, e isso facilitava o entendimento e acompanhamento do processo. Tal entendimento dizia respeito que o AVALIE era somente um critério a ser avaliado dentro de um sistema como um todo, que merecia ser revisto tendo em vista as inúmeras atividades da instituição e que o mesmo não poderia ser aplicado da mesma forma para o ensino de graduação e pós-graduação, como exemplo.

De um modo geral, percebe-se que a instituição utiliza os resultados da avaliação para o seu aprimoramento profissional, onde criou algumas unidades institucionais que são responsáveis pelo apoio junto ao professor e áreas administrativas como o Ensino Integrado.

(...) os professores podem também fazer aulas virtuais via EAD tudo dentro do portal que a gente esta chamando de portal universitário que vai estar dentro do novo setor, uma nova área que foi criada, o ensino integrado. Ali são melhorias que estão acontecendo para a questão do xerox. A biblioteca sofreu uma reestruturação no layout de maneira que atenda melhor o aluno, então também tem essa questão (Entrevista com o Coordenador da CPA, set, 2007).

Segundo o relatório de avaliação da instituição, "o que é possível ser verificado, é que a avaliação institucional está trazendo o conceito de organização de dados e informações de forma a estruturar as ações da Instituição de maneira planejada” (FSG, Relatório da Avaliação Institucional, 2006, p. 97).

De um modo geral, os dados revelam a preocupação constante da FSG no atendimento das necessidades de seu corpo institucional. Os esforços empreendidos revelam um crescimento constante em termos de capacitação e qualificação do quadro docente e administrativo, infraestrutura e novas tecnologias de gestão. Tais indicadores proporcionam, 
por sua vez, uma base sólida para o ingresso de novas formas de gerenciamento e a introdução de ferramentas capazes de auxiliar na gestão e otimização de processos. O modelo aplicado pela instituição revela ser útil na medida em que é compreendido e assimilado. Desta forma, estratégias que proporcionem e estimulem o debate devem ser planejados pela instituição.

\subsubsection{Aspectos de Desempenho}

Em relação ao modelo integrado foi perguntado aos entrevistados o nível de conquista que foi obtido em relação ao cumprimento da proposta do modelo, tendo em vista que o mesmo não propõe somente uma estrutura para avaliação, solicitando que a instituição avance para o planejamento. Neste item oportuno enfatizar a dificuldade das IES, de um modo geral, em integrar avaliação ao planejamento, tendo em vista que ainda se detêm no levantamento de dados e suas respectivas análises para cumprir as exigências da avaliação. Em pesquisa realizada por Leite, Rodrigues e Rizatto (2007), as IES com até 500 alunos ainda cumpriam a análise de algumas das dimensões, dentre elas, a avaliação do corpo docente, infraestrutura e projeto pedagógico, em sua grande maioria, demonstrando a dificuldade de coleta e análise das outras dimensões institucionais solicitadas pelo SINAES.

(...) até agora eu diria que a preocupação foi mais na avaliação, mas direcionou tanto avaliação como planejamento. Direcionou as diretrizes fundamentais da instituição e parece que tem ali um foco mais orientado pra isso e também serviu para sedimentar indicadores importantes sobre o desempenho do professor, sobre o desempenho da instituição, sobre a avaliação dos alunos. Então auxilia muito o planejamento como um todo e as melhorias sugeridas para a instituição desde planejamento. A gente permanentemente tem que aplicar, avaliar e reaplicar, então há uma corrente contínua entre o que é feito e o que precisa ser refeito para ser melhorado. Para cada uma dessas partes do processo tem que haver um planejamento, tem que haver um recurso, tem que haver um tempo para execução e isso que está sendo realizado agora (Entrevista com o Diretor da Faculdade, set, 2007).

(...) o modelo, me parece que pode aprimorar, afinar a parte do planejamento com a parte da avaliação. A gente não tem ações escritas, definidas de cada um dos setores que depois permita serem avaliadas. Acho que aqui é uma área que pode ser, eu não diria problema do modelo mas, mais na operacionalização do modelo e assim é uma dificuldade talvez mais operacional. Mas o modelo em si, aparentemente, ele atende ao que se precisa (Entrevista com o Diretor da Faculdade, set, 2007).

Rev. GUAL., Florianópolis, v.4, n. 2, p.29-52, mai/ago. 2011 
Quanto às dificuldades encontradas no processo, os relatos a seguir demonstram expectativas, ansiedades e angústias em relação ao mesmo. Levantou-se inúmeras contribuições que podem vir a subsidiar o processo crítico-reflexivo da instituição, completando o ciclo PDCA proposto no modelo que prevê um momento de discussão acerca de fatores positivos e negativos que interferiram no processo. Tais indicadores remetem para um melhor aperfeiçoamento e mudanças em alguns procedimentos adotados pela instituição. Pode-se dizer que os relatos sinalizam mudanças em aspectos referentes as tecnologias, estruturas e/ou pessoas.

(...) a dificuldade do modelo é conseguir ter pessoas que realmente compreendam a proposta e possam operacionalizar e criar os instrumentos para que o modelo possa ser implementado (Entrevista com a Representante Docente A da CPA, set, 2007).

(...) a questão de coleta das informações. Por que a instituição está crescendo e junto com o crescimento vão surgindo processos e dentro desses processos eles têm que ser avaliados e muitas vezes algumas pessoas acabam trocando de setor ou acabam se desligando da instituição. Então essa questão de coleta de informações via planilhas, ela se mostrou eficiente para um determinado momento. É a questão de que atendeu as exigências de fazer o primeiro relatório. A partir do primeiro relatório, já se percebeu que as planilhas, elas não são tão eficientes assim. Ela é uma planilha que o coordenador preenche e passa para a Secretaria de avaliação que recoloca as informações numa planilha única e então acontece muito trabalho para fazer essa coleta de informação. Então hoje a maior dificuldade ainda é a questão coleta (Entrevista com o Coordenador da CPA, set, 2007).

(...) na verdade a dificuldade que a gente sentiu é que a forma de como os dados estavam distribuídos, eles não estavam preparados para responder aquelas perguntas dos indicadores, então, de repente eu precisava ali saber qual é o investimento por curso e a gente tem os investimentos controlados mas eles não estavam registrados por curso. Então, depois disso o que que a gente fez? A gente, hoje a biblioteca, a biblioteca tem, quando é adquirido um acervo pro curso de direito a gente já está alocando pro direito. Então a gente naquela época, a dificuldade foi separar, algumas perguntas a gente nem conseguia responder. E depois a gente organizou porque sabia que aquela pergunta tinha sido feita e a gente ficou sem resposta e daquele momento em diante a gente já trabalhou o armazenamento de algumas informações já pensando na avaliação (Entrevista com a representante técnico-administrativa C da CPA, nov, 2007).

No que se refere às facilidades encontradas no processo, apresenta-se algumas opiniões relevantes. 
(...) é que o sistema está montado. Temos na instituição já desenvolvido um setor, orientado pelo Coordenador da CPA, que tem uma cultura de avaliação, quer dizer, cada um dos professores têm a sua planilha de avaliação, então isso circula. Faz parte da melhoria contínua do processo. Então essa cultura ela já existe e está nos ajudando (Entrevista com o Diretor da Faculdade, set, 2007).

(...) a gente cresceu também na questão do volume de indicadores que nós tínhamos. Hoje, também, o sistema que a gente está implantando, a gente também já está implantando pensando nessa possibilidade de extração dos dados, porque o que dificultou ali a primeira avaliação que nós fizemos foi realmente buscar os dados, eles não estavam no formato que era necessário (Entrevista com a representante técnico-administrativa $\mathrm{C}$ da CPA, nov, 2007).

Em relação aos fins efetivos que o modelo teve na avaliação e no planejamento, os relatos sinalizam para a estruturação de áreas dentro da instituição, tendo o Ensino Integrado como um dos pilares do processo.

(...) ele foi utilizado para o planejamento. Agora, lógico, que entre o processo de avaliação e planejamento, aqui tem um degrau que é quase que um abismo porque o processo de avaliação, como é ele um pré-requisito do MEC, ele tem que ser feito, então ele vai sendo feito, mesmo que as vezes a gente de mais ênfase à avaliação dos alunos, no avalie, mas as demais, o censo, tudo está ali. Só que o planejamento, ele vai muito mais lento. Só que então os ajustes vão sendo feitos a partir dos resultados que a gente tem nas cinco dimensões da avaliação. Mas eles são muito bem alinhados com o planejamento estratégico (Entrevista com a Representante Docente A da CPA, set, 2007).

(...) a avaliação, o modelo vem efetivar os processos que estão acontecendo na FSG, então ela tem servido para refletir e encaminhar as ações. No entanto, o planejamento estratégico da instituição, ele também tem acontecido muito lentamente, mesmo que articulado com a avaliação, mas eu não tenho visto efetivamente com exceção do avalie o resultado da avaliação do planejamento (Entrevista com a representante docente A da CPA, nov, 2007).

Observou-se, de um modo geral, que a instituição está muito focada em avaliar o ensino de graduação, que ainda é o foco principal. Tendo em vista a necessidade de organizar os processos de modo a cumprir o modelo, assim como o relatório de avaliação a ser enviado ao INEP, a instituição ainda apresenta morosidade em conseguir fazer com que o ciclo gire, ou seja, que não fique somente na avaliação, mas que os resultados obtidos sejam levados para o planejamento. Pode-se dizer que, muitas melhorias estão sendo efetuadas, frutos dos 
dados da avaliação, mas são melhorias pontuais. É necessário que os dados da avaliação efetivamente levem a comunidade acadêmica à reflexão sobre o ensino superior e sobre quais são os rumos da instituição em todas as dimensões: ensino de graduação, pós-graduação, pesquisa, extensão e gestão.

Neste sentido, importante se faz o relato apresentado no relatório de avaliação institucional encaminhado ao Governo no ano de 2006 pela instituição, onde nas conclusões refere:

A demora no levantamento das informações também dificultou a tomada de decisões e a continuidade das ações planejadas. Após a coleta de informações, a CPA e a secretaria da avaliação nortearam a interpretação e a organização das informações obtidas, em um processo de aprendizagem sujeito a erros que iam sendo corrigidos pela equipe técnica. As chefias de áreas, devido à priorização de outras atividades, embora conscientes da importância do trabalho e dispondo-se a isto, pelo volume dos dados da avaliação demoraram mais do que o previsto, dificultando, involuntariamente, a compilação dos dados. Novamente, sublinhamos a importância de reforçarmos os resultados da avaliação como ferramentas de gestão, contribuindo no estabelecimento da cultura e na fluidez do processo internamente (FSG, Relatório de auto-avaliação, 2006, p. 96).

\subsubsection{Aspectos Emergentes}

Em relação à opinião dos entrevistados quanto ao processo de avaliação antes e depois do modelo aplicado.

(...) esse processo deu uma consistência a diferentes dimensões. Antes nós tínhamos a avaliação, mas era uma avaliação mais do aluno, sobre os desempenho dos professores, e também tínhamos uma avaliação financeira, como é que financeiramente a instituição está desempenhando. Com as diferentes dimensões, então nós entramos na parte pedagógica operacional, entramos nas diferentes áreas. Isso nos deu uma visão mais sistêmica da instituição, isso parece, a contribuição que a avaliação está acrescentando, agora, na estrutura que está hoje, ela está dando a visão mais sistêmica, mais do todo da organização. E evidente que os pontos de vantagens é a melhoria da cada um deles. Se nós enxergarmos o todo, mas não atuarmos aonde está o problema, não vai ajudar muito (Entrevista com o Diretor da Faculdade, set, 2007).

(...) como é que a gente enxerga esse modelo? as dimensões estruturadas para a FSG ela atende totalmente as necessidades institucionais e as diretrizes mantidas e propostas pelo MEC. Na FSG nós vamos terminar o último ciclo esse ano, fechando o ciclo de avaliação e a dificuldade foi realmente em criar procedimentos para que as pessoas responsáveis pelos setores e as pessoas envolvidas no processo possam dar as informações.

Rev. GUAL., Florianópolis, v.4, n. 2, p.29-52, mai/ago. 2011 
Agora o modelo, ele é inquestionável, acho que ele tem que ser mantido, inclusive a minha colocação na instituição enquanto membro efetivo e uma pessoa que participa totalmente do processo é que a gente não altere o modelo, mas que a gente aprofunde e realmente reorganize as questões para cumprir a proposta efetivada (Entrevista com a Representante Docente da CPA, set, 2007).

(...) Antes a gente tinha um processo de avaliação que era restrito a avaliação do aluno, a gente só tinha índices ou indicadores ou variáveis que os alunos percebiam e com o modelo de avaliação, não, além da percepção do aluno que é um elemento, você tem a possibilidade de avaliar gestão, avaliar extensão, avaliar investigação, avaliar o ensino, você tem todas as possibilidades, de não só através da percepção do aluno, mas de ter essas outras, as outras dimensões avaliadas (Entrevista com a representante docente A da CPA, nov, 2007).

Quando indagados aos entrevistados sobre às perspectivas futuras com relação à avaliação e o planejamento institucional, os entrevistados relataram diversos aspectos interessantes sobre o modelo aplicado.

(...) é integrar ao planejamento, consolidar essa parte do sistema, ao novo sistema RM e ver até que ponto é possível, até através da avaliação. Ver uma remuneração variável para os coordenadores e professores. Me parece que há uma tendência, ou pelo menos uma expectativa de divisão de resultados, no sentido de melhorar o desempenho da instituição e aperfeiçoar o sistema que está aí. Seria através de melhorias incrementais ao sistema (Entrevista com o Diretor da Faculdade, set, 2007).

(...) se a gente tiver pessoas que conduzam o processo e tenham compreensão da complexidade e da grandeza que é o modelo de avaliação eu acredito, num futuro muito breve, que a gente pode ter perspectivas excelentes para resolver vários problemas que são decorrentes dessas, que estão na avaliação. E inclusive fazer a relação do modelo de avaliação com o planejamento, agora eu só consigo enxergar isso, numa forma diferente de conduzir o processo (Entrevista com a representante docente A da CPA, nov, 2007).

Enfatiza-se que os relatos apresentados revelam parte das contribuições dadas pelos participantes entrevistados, outras tantas foram analisadas e inseridas no modelo, tendo em vista que revelam aspectos importantes da vida institucional. Com certeza, a contribuição através da pesquisa qualitativa foi fundamental para o aprimoramento e conhecimento de todas as variáveis que poderiam influenciar no desempenho do modelo. 


\section{CONSIDERAÇÕES FINAIS}

Pode-se concluir em relação a aplicação do modelo integrado de avaliação ao planejamento anual na FSG que a instituição vem desenvolvendo seu processo avaliativo de forma bastante comprometida com a busca de qualidade institucional, preocupando-se em integrar os processos avaliativos que são desenvolvidos por dimensão 'ensino de graduação, ensino de pós-graduação, pesquisa, extensão e gestão'. No entanto, ainda precisa empreender esforços para a integração do processo de avaliação ao processo de planejamento (Quarto pilar do modelo). Após várias medidas para aperfeiçoamento do processo, a Faculdade está reavaliando suas ações, tendo em vista a sistematização dos procedimentos de avaliação e planejamento. As entrevistas permitiram avaliar aspectos importantes do modelo, como os relatados a seguir.

(i) necessidade da instituição rever o perfil dos membros integrantes da comissão própria de avaliação (CPA);

(ii) necessidade de treinamento/ capacitação acerca do modelo aos membros da CPA;

(iii) necessidade de divulgação ampla do modelo avaliativo à comunidade acadêmica para que não entendam avaliação como sinônimo do AVALIE.

(iv) necessidade de compatilizar os resultados da avaliação ao planejamento de curto e longo prazo da instituição;

(v) necessidade de focar esforços em outras dimensões da avaliação que não somente o ensino de graduação;

(vi) necessidade de rever indicadores de avaliação da dimensão pós-graduação;

(vii) necessidade de conscientizar a comunidade acadêmica da importância de manter uma cultura de avaliação e que seus benefícios podem ser amplamente utilizados em prol da melhoria do ensino superior;

(viii) necessidade de organizar reuniões regulares da comissão de avaliação e das subcomissões de avaliação, impulsionando o cumprimento dos pilares do modelo avaliativo;

(ix) necessidade de rever os ciclos avaliação-planejamento, que no modelo adotado prevê um limite de tempo de 3 em 3 meses para que ocorra a avaliação de cada dimensão (ensino de graduação, ensino de pós-graduação, pesquisa, extensão e gestão) 
remetendo a mesma ao planejamento. Tal proposta deve-se ao fato de que caso os setores não se conscientizem em repassar as informações necessárias à CPA, o ciclo não é cumprido atrasando todo o processo;

(x) necessidade de rever alguns indicadores quantitativos e qualitativos, na sua forma de coleta de dados.

Acredita-se que a partir da revisão e acréscimo destes elementos junto ao modelo proposto, a instituição tenha condições de efetivamente cumprir todo o ciclo proposto pelo modelo, não detendo-se simplesmente em avaliar, mas sim que esta avaliação seja conduzida ao processo de planejar, em todas as suas dimensões. Necessário lembrar que a avaliação institucional pressupõe o avaliar toda a estrutura da instituição, todas as pessoas e todos os processos. Não será possível um conhecimento da totalidade institucional sem o conhecimento prévio das partes que integram essa estrutura e as formas como elas interagem entre si.

Neste sentido, importante enfatizar o pensamento de Dias Sobrinho e Balzan (1995, p. 9) quando mencionam que, além das práticas avaliativas pontuais e fragmentadas, a avaliação consiste num empreendimento sistemático que busca a compreensão global da universidade, pois ela é "uma instituição pluralista e multidimensional que se constrói nos movimentos das relações de forças. Para compreendê-la, é necessário buscar o entendimento das redes de significações múltiplas e o conjunto de processos e relações que se produzem em seu cotidiano".

De um modo geral, considerando os enfoques utilizados para a melhor compreensão dos temas 'avaliação e planejamento', acredita-se que a proposta deste trabalho pode ser de grande utilidade às instituições que estão envolvidas com o processo de avaliação institucional e preocupadas em adequar essa estrutura ao planejamento institucional. Ressaltase, novamente, a preocupação da autora em propor uma abordagem de integração do processo de avaliação ao planejamento institucional. Desenvolver soluções para esse tema é urgente, tendo em vista os relatos obtidos e a premência dos fatos. No momento atual, observa-se que o Estado através de seu poder de regulação está forçando às instituições a se adequarem às suas 'condições de qualidade'. 
A pesquisa evidenciou a necessidade de que ambos os processos aconteçam de forma integrada, fazendo com que as ações conduzam à excelência institucional. O modelo apresentado busca responder à necessidade evidenciada na literatura, assim como na preocupação da instituição estudada, sendo aplicável a qualquer tipo de instituição de educação superior, de natureza pública ou privada.

\section{REFERÊNCIAS}

BITTAR, Mariluce. O ensino superior privado no Brasil e a formação do segmento das universidades comunitárias. Avaliação, Campinas, ano 6, v. 6, n. 2 (20), p. 33-42, jun. 2001.

DIAS SOBRINHO, José; BALZAN, Newton César. Avaliação institucional: teoria e experiências. São Paulo: Cortez, 1995.

KAPLAN, Robert S.; NORTON, David P. A estratégia em ação. Rio de Janeiro: Campus, 1997.

LEITE, D.; RODRIGUES, C. M. C.; RIZZATO, E. P. O desempenho de auto-avaliação das pequenas IES. Relatório de pesquisa. Edital MEC/INEP, nº. 2006-028, 2007.

MEC/INEP. SINAES - Roteiro de Auto-avaliação institucional 2004. Brasília/DF, 2004.

RELATÓRIO DA AVALIAÇÃO INSTITUCIONAL DA FACULDADE DA SERRA GAÚCHA - FSG - 2003-2005. Caxias do Sul: FSG, 2006.

RODRIGUES, Cláudia Medianeira Cruz. Proposta de avaliação integrada ao planejamento anual: um modelo para as UCGs. 2003. Tese (Doutorado em Engenharia de Produção) - Universidade Federal do Rio Grande do Sul, Programa de Pós-graduação em Engenharia de Produção, Porto Alegre, RS.

THIOLLENT, Michel. Metodologia da pesquisa-ação. 14aed. São Paulo: Cortez, 2005.

YIN, Robert K. Estudo de caso: planejamento e métodos. Porto Alegre: Bookman, 2001. 


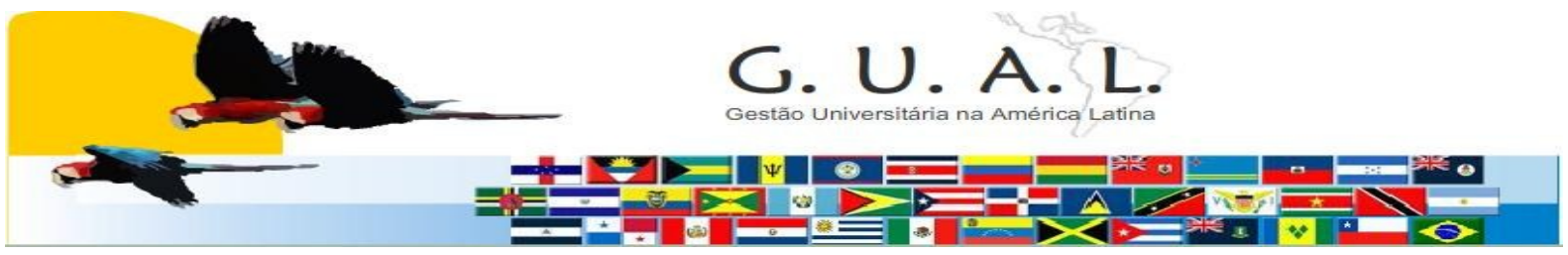

ISSN 1983-4535

\title{
AN APPLICATION OF THE EVALUATION MODEL INTEGRATED TO ANNUAL STRATEGIC PLANNING IN THE FACULDADE DA SERRA GAÚCHA (FSG): A CASE STUDY
}

Cláudia Medianeira Cruz Rodrigues, Doctor

Universidade Federal do Rio Grande do Sul

claudia.rodrigues@producao.ufrgs.br

\begin{abstract}
The purpose of this paper is to verify how Rodrigues (2003) evaluation model integrated to annual strategic planning works within a private higher education institution. Thus, it will be possible to observe the performance of the model's key evaluation and planning elements, that is, (i) integration between evaluation and planning elements, (ii) use of planning-oriented indicators, (iii) scheduling of annual planning and evaluation activities; (iv) establishment of the integrated cycle of planning and evaluation; and (iv) integration of human resources in planning and evaluation processes. Data collection was performed in two steps: (1) case study conducted in the Faculdade da Serra Gaúcha/Caxias do Sul-RS in the period between 2004 and 2006; and (2) semi-structured interviews with the Assessment Committee, involving teacher, student and faculty representatives. Results support model validity for this HEI segment, with minor operational adjustments. It was verified that the model's element (v) was the most relevant one regarding the conduction of the analyzed processes. In particular, there was observed difficulties related the factual comprehension about the concept of "institutional evaluation" and the importance of creating awareness in the sectors regarding the provision of information requested by the Committee on time. Thus, other elements of the proposed model were harmed by the lack of an institutional culture that perceives the evaluation-assessment as a continuous, constantly improving cycle.
\end{abstract}

Keywords: Institutional evaluation. Annual planning. SINAES. 